

Revista Comportamento do Consumidor
Maciel, A. C. S., Cardoso, J. G., \& Sousa Júnior, J. H. (2020). Relacionando Funções das Marcas e Fatores de Influência Internos dos Usuários: Estudo netnográfico em comunidades virtuais. Consumer Behavior Review, 4(2), 146-161.
ISSN: 2526-7884

Editor: Prof. Dr. Marconi Freitas da Costa Journal's e-mail: cbr@ufpe.br
Evaluation: Double blind review

Received: 12 de fevereiro de 2020

Accepted: 27 de maio de 2020

\title{
RELACIONANDO FUNÇÕES DAS MARCAS E FATORES DE INFLUÊNCIA INTERNOS DOS USUÁRIOS: ESTUDO NETNOGRÁFICO EM COMUNIDADES VIRTUAIS
}

\begin{abstract}
Relating Brand Functions and Internal User Influence Factors: Netnographic study in virtual communities
\end{abstract}

\author{
Alan César Souza Maciel ${ }^{1}$ \\ ORCID: https://orcid.org/0000-0003-2440-1469 \\ E-mail: alancsmaciel@yahoo.com.br \\ Janaína Gularte Cardoso 2 \\ ORCID: https://orcid.org/0000-0002-2017-1304 \\ E-mail: janaina.cardoso@uffs.edu.br \\ João Henriques de Sousa Júnior ${ }^{2}$ \\ ORCID: https://orcid.org/0000-0001-8589-8101 \\ E-mail: sousajunioreu@hotmail.com
}

\footnotetext{
${ }^{1}$ Departamento de Administração, Universidade Federal da Fronteira Sul, Chapecó, Brasil ${ }^{2}$ Programa de Pós-Graduação em Administração, Universidade Federal de Santa Catarina, Florianópolis, Brasil
}

\begin{abstract}
Resumo
Conhecer as influências que determinam as escolhas dos consumidores é primordial para que os profissionais de marketing possam propor estratégias às organizações. Um dos recursos para essa compreensão está no entendimento das comunidades virtuais, dada
\end{abstract}

\begin{abstract}
Knowing the influences that determine consumer choices is paramount so that marketers can propose strategies to organizations. One of the resources for this understanding is the understanding of virtual communities, given their importance in
\end{abstract}


sua importância na contemporaneidade. Assim, este trabalho objetiva compreender as funções das marcas e os fatores de influência internos para os usuários de comunidades virtuais de três grandes marcas. Para tanto, realizou-se uma pesquisa mista por meio de netnografia. Os dados foram obtidos de forma arquivais e extraídos por meio de questionários nas comunidades virtuais, sendo submetidos à análise de conteúdo e estatística descritiva. Os resultados evidenciam que o posicionamento adequado das marcas propicia a percepção das funções exercidas para seus usuários. Infere-se que as organizações devem conhecer como as funções de suas marcas são desempenhadas e como os consumidores se comportam perante elas, para que possam elaborar estratégias mais assertivas e obter maior retorno.

Palavras-chave: Funções da marca, Fatores internos dos consumidores, Comunidades virtuais, Netnografia. contemporary times. Thus, this work aims to understand the functions of brands and the internal influencing factors for users of virtual communities of three major brands. For this, a mixed research was carried out through netnography. The data were obtained in archival form and extracted through questionnaires in the virtual communities, being submitted to content analysis and descriptive statistics. The results show that the proper positioning of the brands provides the perception of the functions performed for its users. It is inferred that organizations must know how the functions of their brands are performed and how consumers behave towards them, so that they can develop more assertive strategies and obtain greater return. Keywords: Brand functions, Internal consumer factors, Virtual communities, Netnography.

Esta obra está licenciada com uma Licença Creative Commons Atribuição 4.0 Internacional.

\section{INTRODUÇÃO}

As marcas são interessantes sob diversas perspectivas, devido a pluralidade de significados incorporados, refletindo assim no modo como o indivíduo a percebe. Ao encontro disso, Aaker (1998) defende que a marca caracteriza uma fonte sustentável de vantagem competitiva, pois reflete para os consumidores as razões pelas quais devem comprar determinada marca. Ademais, Fournier (1998) defende que uma das formas de se legitimar a marca como parceira do consumidor é evidenciar o modo através do qual as marcas são personalizadas ou ainda humanizadas.

Há séculos as marcas tiveram a finalidade apenas de identificação, mas hoje elas desempenham funções muito mais elaboradas em benefício do consumidor (Urdan \& Urdan, 2013). Dessa forma, a marca exerce diversas funções que justificam a sua atratividade e seu retorno financeiro, principalmente quando são valorizadas pelos consumidores (Kapferer, 2008). Além disso, no contexto social atual, em que a web 2.0 propiciou ferramentas mais dinâmicas, as marcas buscam cada vez mais apropriar-se dessas ferramentas para garantir interatividade com os consumidores. Isto porque, como afirma Ariely (2000), uma das principais vantagens de ter um alto nível de interatividade com os indivíduos é a maior previsibilidade nas ações desenvolvidas pela marca.

Desse modo, é imprescindível examinar os fatores que influenciam a compra e o consumo. De modo geral, esses fatores de influência se agrupam em dois: os fatores externos e os fatores internos. Fatores externos ao indivíduo emitem estímulos para ele, que são processados levando em conta os fatores internos à pessoa (Urdan \& Urdan, 2010). Assim, os fatores de influência internos dos consumidores possuem destacada importância no processo compra.

Nesse contexto, percebe-se que a mídia, cada vez mais globalizada e acessível, e as mudanças de comportamento de consumo passam a exigir a adoção de técnicas avançadas de pesquisa e projeção para novos e inusitados hábitos de consumo. Por estas razões, "o futuro do marketing passa pela virtualidade" (Cobra, 2009, p. 18).

Dentro do universo virtual, as marcas começaram a criar perfis e personificações, adotando aspectos reais dentro do virtual. Com esse movimento de inserção online, os pesquisadores 
começaram a se interessar pelas dinâmicas de marketing, relacionamento e consumo dentro do ambiente virtual. Assim, surgiram, inclusive, formas de se realizar pesquisas nesse cenário, dentre elas, a netnografia, que Kozinets (2014, p. 10) afirma ser amplamente aceita em vários tópicos de interesse, uma vez que "nossos mundos sociais estão se tornando digitais".

Diante do exposto, entende-se que o estudo das comunidades virtuais pode contribuir significativamente em pesquisas mercadológicas, gerando novos conhecimentos e proporcionando benefícios nos campos científico e gerencial. Então, visando compreender a forma como as marcas se comportam no ambiente online e a forma como os usuários a percebem neste contexto, tem-se como problema de pesquisa a seguinte questão: Como os usuários de comunidades virtuais identificam as funções das marcas e quais os seus fatores de influência internos?

Assim, com o propósito de elucidar o problema exposto, formulou-se, como objetivo de pesquisa, compreender as funções das marcas e os fatores de influência internos para os usuários de comunidades virtuais das marcas Itaú, Skol e Natura. Tais marcas foram selecionadas por se apresentarem como mais representativas e valiosas dentro de suas categorias, conforme a Interbrand (2016). Assim, com base nesses dados, dentro da categoria de serviços financeiros destacava-se a marca Itaú; dentro da categoria de bebidas destacava-se a marca Skol; e, por fim, na categoria de cosméticos, a marca que mais se destacou foi a Natura (Interbrand, 2016).

Este artigo está dividido em cinco seções, incluindo esta introdução. A segunda seção refere-se à fundamentação teórica, abordando conceitos relacionados ao comportamento do consumidor, funções das marcas e comunidades virtuais. Na terceira seção explana-se a metodologia da pesquisa, e na quarta seção, apresenta-se os resultados e a discussão. Por fim, na quinta seção são abordadas as considerações finais, destacando-se as contribuições desta pesquisa.

\section{FUNDAMENTAÇÃO TEÓRICA}

Para atingir o propósito desta pesquisa fez-se necessário o entendimento de alguns conceitos advindos do marketing. Para tanto, neste capítulo de fundamentação teórica, inicialmente abordam-se teorias sobre o comportamento do consumidor, em seguida apresentam-se conceitos de marca e suas funções, e, por último, abordam-se as definições de mídias sociais, redes sociais e comunidades virtuais.

\section{Comportamento do Consumidor}

Muitos estudiosos do comportamento do consumidor têm procurado definir de forma implícita ou explícita o que é comportamento do consumidor. As principais discussões estão centradas nos diferentes tipos de conhecimento buscados e na utilização de diferentes metodologias de pesquisa. Assim sendo, o significado ontológico da pesquisa do consumidor o estabelece como "[...] o estudo dos processos onde há aquisição, uso e disposição de todos os tipos de produtos que têm valor para aquilo que o homem deseja" (Holbrook, 1987, p. 131).

Em termos de pesquisa de marketing, o comportamento do consumidor é pensado como o estudo da motivação pela qual as pessoas realizam o ato de compra, sob a perspectiva de que é mais fácil elaborar estratégias quando se entende porque as pessoas compram determinados produtos ou marcas (Blackwell, Miniard \& Engel, 2011). Neste sentido, Urdan e Urdan (2010) afirmam ser imprescindível examinar os fatores que influenciam a compra e o consumo, o processamento realizado pelo próprio indivíduo e também os modos de pensar e sentir que levam a decisões. Estes autores ainda apresentam o modelo de comportamento do consumidor baseado em fatores externos e internos. Por estarem intrinsicamente relacionados ao consumidor, os fatores de influências internos são relevantes nas pesquisas mercadológicas, tais fatores são explanados a seguir.

Os fatores de influência internos dos consumidores, compreendem os seguintes vetores: motivação, necessidades e desejos; atitudes; valores pessoais e estilo de vida (Urdan \& Urdan, 2010). Cada um desses fatores é explanado mais adiante. Rocha, Ferreira e Silva (2012), apresentam os domínios motivacionais desenvolvidos por Schwartz e Bilsky (1990), que foram testados em consumidores de várias nacionalidades e foram consideradas apropriadas para descrever as 
motivações humanas. 0 modelo compreende as seguintes categorias: pró-social; conformidade restritiva; prazer; realização; maturidade; auto direcionamento; segurança.

Além deste, outro modelo, mais conhecido e referenciado de necessidades humanas, é a hierarquia de necessidades de Maslow (1943), que propõe o agrupamento em cinco categorias sucessíveis: necessidades fisiológicas; necessidade de segurança; necessidades sociais; necessidade de estima; necessidade de auto realização (Rocha, Ferreira \& Silva, 2012). Diferente das necessidades, os desejos dos indivíduos podem ser compostos de duas partes: explícito ou oculto. 0 desejo explícito está no nível consciente dos indivíduos sendo expressos verbalmente, enquanto o desejo oculto está no inconsciente, portanto, as pessoas não conseguem verbalizar ou expressar sem penetrar na sua mente (Cobra, 2009).

Outro fator interno, a atitude, representa o que gostamos e o que não gostamos, normalmente fazemos o que gostamos e evitamos o que não gostamos (Blackwell, Miniard \& Engel, 2011). Urdan e Urdan (2010), apresentam o modelo de Solomon (2002), o qual demonstra que a atitude abrange três componentes inter-relacionados: cognitivo, afetivo e conativo. 0 cognitivo refere-se aos pensamentos do consumidor, o afetivo refere-se as emoções despertadas e o conativo é a intenção de comportamento, todos acerca do objeto.

Ao contrário das atitudes, os valores pessoais transcendem as situações ou eventos e são mais duradouros pelo fato de serem mais centrais na estrutura da personalidade (Blackwell, Miniard \& Engel, 2011). Urdan e Urdan (2010), apresentam uma tipologia de valores bem aplicada ao marketing que foi proposta por Schwartz (2005), ela abrange as seguintes dimensões de valor: poder; realização; hedonismo; estimulação; auto direção; universalismo; benevolência; tradição; conformidade; segurança.

Como último fator interno de comportamento do consumidor tem-se o estilo de vida, que é o padrão de vida de uma pessoa expresso pelas suas atividades, interesses e opiniões. Neste caso, as atividades correspondem ao que o indivíduo faz nas diversas esferas da vida, aplicando seu tempo e dinheiro; os interesses apontam aquilo que mais atrai a pessoa no entorno imediato; e as opiniões indicam como o indivíduo pensa e se sente, exprimindo a visão que a pessoa tem de si mesma e do mundo ao seu redor (Urdan \& Urdan, 2010). Explicitados os conceitos acerca do comportamento do consumidor, o próximo tópico se dedica ao estudo da marca e sua relação com os consumidores.

\section{A Marca e Suas Funções para os Consumidores}

Para Wood (2000), segundo a American Marketing Association (1960), uma marca é definida como um nome, termo, sinal, símbolo ou desenho, ou uma combinação deles, destinados a identificar os bens ou serviços de um vendedor ou grupo de vendedores e a diferenciá-los dos concorrentes, e essa combinação de fatores determina a identidade da organização. Do ponto de vista mercadológico, as marcas são valiosos ativos intangíveis que precisam ser gerenciadas cuidadosamente, uma vez que na atualidade, as empresas lutam para estabelecer uma marca sólida por meio de sua imagem. Por este motivo, assim como apontado por Aureliano-Silva (2017, p. 2), os estudos em marketing evidenciam a marca "como o principal atributo que o consumidor considera para avaliação de um produto e decisão de compra".

Do ponto de vista etimológico, o termo em inglês "brand" se origina do nórdico antigo "brandr" que significava queimar, isso porque as marcas a fogo eram usadas pelos proprietários de gado para marcar e identificar seus animais (Keller \& Machado, 2006). As marcas desempenham importante papel social, proporcionando a expansão de sua comunicação na sociedade contemporânea. "Quando pensamos na presença das marcas em nossa sociedade contemporânea, a primeira ideia que vem à mente não é a qualidade dos produtos, mas a intensidade das mensagens" (Chevalier \& Mazzalovo, 2007, p. 40).

De acordo com Aaker, Fournier e Brasel (2004), o relacionamento entre a marca e o consumidor ocorre por meio de fatores comportamentais e psicológicos dos indivíduos, o que envolve memórias cognitivas e afetividade desenvolvidos com a marca. Além disso, as marcas fornecem significados que permitem aos indivíduos transmitir status, prestígio ou identificação social e ainda fazem com que a marca seja associada à sua imagem (McCracken, 2011). Neste sentido, diferentes 
consumidores podem pensar em diferentes associações de marca, mas muitas provavelmente são compartilhadas pela maioria deles. Entretanto, essa imagem pode variar, dependendo dos grupos específicos de consumidores ou dos segmentos de mercado envolvidos (Keller \& Machado, 2006).

Ademais, verifica-se que "a marca não é somente fonte de informações (revelando, portanto, seu valor), mas realiza algumas funções típicas, justificando sua atratividade e sua contrapartida monetária (preço premium), quando ela é valorizada pelos compradores". (Kapferer, 2003, p. 24). Em uma visão aprofundada e estruturada, Kapferer (2003), apresenta uma gama de funções exercíveis por uma marca em benefício do consumidor. A Tabela 1 apresenta estas funções e seus respectivos benefícios ao consumidor.

Tabela 1

Funções da marca para os consumidores

\begin{tabular}{l|l}
\multicolumn{1}{c}{ Função } & \multicolumn{1}{c}{ Benefício ao consumidor } \\
\hline De referência & $\begin{array}{l}\text { Ver claramente, situar-se em relação à produção setorial, identificar rapidamente } \\
\text { os produtos procurados. }\end{array}$ \\
\hline De praticidade & $\begin{array}{l}\text { Permitir ganho de tempo e de energia na recompra de produto idêntico pela } \\
\text { fidelidade. }\end{array}$ \\
\hline De garantia & $\begin{array}{l}\text { Segurança de encontrar uma qualidade estável em todos os lugares e a todo } \\
\text { instante. }\end{array}$ \\
\hline De otimização & $\begin{array}{l}\text { Segurança de comprar o melhor produto de sua categoria, com o melhor } \\
\text { desempenho. }\end{array}$ \\
\hline De personalização & $\begin{array}{l}\text { Sentir-se reconfortado com sua autoimagem ou com a imagem que é passada aos } \\
\text { outros. }\end{array}$ \\
\hline De permanência & $\begin{array}{l}\text { Satisfação nascida da familiaridade e da intimidade das ligações com uma marca } \\
\text { que foi consumida durante anos e que ainda dura. }\end{array}$ \\
\hline Hedonista & Satisfação ligada à estética da marca, seu design e suas comunicações. \\
\hline Ética & $\begin{array}{l}\text { Satisfação ligada ao comportamento responsável da marca nas suas relações com } \\
\text { a sociedade (ecologia, emprego, cidadania, publicidade não chocante). }\end{array}$ \\
\hline Fonte: Kapferer (2003, praf)
\end{tabular}

Fonte: Kapferer (2003, p. 24)

As duas primeiras funções, de referência e de praticidade, são consideradas mecânicas, pois dizem respeito à própria essência da marca: ser um símbolo reconhecido para facilitar a escolha e o ganho de tempo (Kapferer, 2003). As três funções seguintes, de garantia, de otimização e de personalização, atuam na redução do risco percebido, as quais são as expectativas subjetivas do indivíduo quanto a perdas associadas a cada alternativa na decisão para atingir uma meta (Kapferer, 2003; Urdan \& Urdan, 2013). As três últimas funções desempenhadas pelas marcas para o consumidor, expressam o prazer proporcionado pela marca e os sentimentos despertados (Urdan \& Urdan, 2013).

Compreendidos os conceitos relacionados à marca, destaca-se um aspecto importante: o consumidor não é mais uma estatística anônima em um relatório, mas sim um participante ativo no processo de construção de marcas. Isso porque os novos mantras são compartilhar, marcar e comentar, assim todos são um pouco produtores, reprodutores, diretores e distribuidores (Wheeler, 2012). Diante disto é relevante compreender as questões referentes as comunidades virtuais, conforme segue no próximo tópico.

\section{Mídias Sociais, Redes Sociais e Comunidades Virtuais}

Diversas são as mudanças proporcionadas pela comunicação desde que o computador passou a mediar as relações sociais. A internet possibilitou, no decorrer das últimas décadas, mudanças significativas na forma como a sociedade se comporta, promovendo transformações na economia, nas formas de consumo e na comunicação (Sousa Júnior, 2018). 0 surgimento das mídias sociais digitais é uma delas, e possui alta significância. Segundo Telles (2011, p. 17) "as mídias sociais fazem parte de uma revolução poderosa, influenciam decisões, perpetuam ou destroem marcas e elegem presidentes" (Telles, 2011, p. 17). 
Mídias sociais são ferramentas que possibilitam a formação de discussões entre as pessoas e empresas na rede, elas permitem uma melhor experiência virtual e promovem a vida em comunidade e a cooperação (Cipriani, 2011). Além disso, as mídias sociais proporcionam um impacto positivo sobre o patrimônio da marca, pois auxiliam as empesas na divulgação da marca e potencializando as interações (Bruhn, Schoenmueller \& Schaffer, 2012).

A ideia de rede social começou a ser usada há cerca de um século para designar um conjunto complexo de relações entre membros de um sistema social em diferentes dimensões (Telles, 2011). Na concepção de Cipriani (2011, p. 5), redes sociais podem ser definidas como "qualquer plataforma que permita às pessoas se conectarem mantendo listas estáveis ou não de relacionamentos para interagir com outras pessoas". Este autor ainda destaca que dentro das redes sociais são formadas as comunidades virtuais, que são as tribos onde pessoas se conectam para conversar sobre assuntos de seu interesse.

As comunidades e fóruns on-line assumem diversas formas e tamanhos, seus membros se comunicam por meio de postagens, mensagens instantâneas e salas de bate-papo. Essas comunidades e fóruns on-line podem ser um recurso valioso para as empresas (Sousa Júnior \& Silva Júnior, 2018). Por tudo que foi exposto, verifica-se que as mídias sociais permitem que os consumidores se envolvam com uma marca em um nível provavelmente mais profundo e mais amplo do que nunca. Assim, o tópico seguinte apresenta os procedimentos metodológicos adotados para a realização deste estudo.

\section{MÉTODO}

A presente pesquisa se caracteriza como de abordagem mista, pois emprega metodologias qualitativas e quantitativas ao fazer uso da pesquisa bibliográfica e da netnografia, também conhecida como etnografia virtual. No tocante à pesquisa bibliográfica, Vergara $(2013$, p. 43) define como "o estudo sistematizado desenvolvido com base em material publicado em livros, revistas, jornais, redes eletrônicas, isto é, material acessível ao público em geral". $\mathrm{Na}$ realização do levantamento bibliográfico, buscou-se as fontes arquivais dos grupos selecionados para compor esta pesquisa e utilizou-se uma abordagem qualitativa, uma vez que buscava-se compreender mais profundamente os detalhes do fenômeno aqui estudado.

$\mathrm{Na}$ sequência, utilizou-se a netnografia, que consiste de uma pesquisa observacional participante com o trabalho de campo online, usando comunicações mediadas por computador como fonte de dados para chegar à compreensão e à representação etnográfica de um fenômeno cultural (Kozinets, 2014). Para tanto, realizou-se abordagem quantitativa, ao mensurar os dados coletados no período de 2015 a 2016, a partir da utilização de questionários estruturados.

0 tipo de netnografia utilizada na presente pesquisa é a participante-observacional, considerando que "a experiência que se tem como um netnógrafo procurará equilibrar o modo reflexivo, autobiográfico e subjetivo do participante cultural, engajado com o objetivo de precisão do observador científico" (Kozinets, 2014, p. 94). O processo da pesquisa netnográfica segue seis passos que advém da etnografia (Kozinets, 2014). A Figura 1 apresenta os passos da pesquisa netnográfica agrupados em quatro fases que foram seguidas para a realização desta pesquisa.

\begin{tabular}{|l|l|}
\hline Primeira fase & •Definição das questões de pesquisa, websites sociais ou tópicos a investigar \\
\hline Segunda fase & •Identificação e seleção de comunidade \\
\hline Terceira fase & • Observação participante da comunidade e coleta de dados \\
\hline Quarta fase & • Análise de dados e interpretação iterativa dos resultados \\
\hline
\end{tabular}

Fonte: Adaptado de Kozinets (2014, p. 63)

Figura 1. Etapas de um projeto de pesquisa netnográfica 
Como pode-se perceber a partir da visualização da Figura 1, antes de ingressar na cultura virtual, Kozinets (2014), destaca que existem algumas coisas importantes a serem definidas, a primeira delas é decidir o que exatamente vai ser estudado, para isto deve-se elaborar e focar questões apropriadas para a netnografia. Por isso, foram formuladas perguntas para este estudo que visassem alcançar resultados que respondessem à pergunta de pesquisa. Assim, seguiu-se para identificação de fóruns eletrônicos, segunda etapa da pesquisa netnográfica, onde foram apresentados e universo e unidades de análise desta pesquisa.

A delimitação do universo consiste em explicitar que pessoas ou fenômenos que possuem características comuns serão pesquisados (Marconi \& Lakatos, 2010). Dessa forma, esta pesquisa tem como universo os usuários de diferentes comunidades virtuais de marcas como blogs, fóruns, redes sociais, entre outros. 0 tipo de amostragem desenvolvida nesta pesquisa é do tipo não probabilística por conveniência. A escolha das marcas, por sua vez, foi baseada no ranking anual de valor das marcas da Interbrand (2016), em que são avaliadas as marcas de origem brasileira que têm informações financeiras públicas por meio de uma metodologia própria que analisa as diferentes formas de influência da marca no desempenho da organização, de acordo com o impacto exercido em consumidores, funcionários, fornecedores e investidores. Assim, dentre as marcas listadas no ranking, foram selecionadas as de maior valor em três categorias diferentes e mais representativas, conforme apresentado pela Interbrand (2016), são elas: Itaú (serviços financeiros); Skol (bebidas); Natura (cosméticos).

Dessa forma, seguiu-se para a escolha dos websites com base no Ranking Alexa (2016) que divulga os sites mais visitados da internet no período que compreendeu essa coleta, que consiste nos anos de 2015 a 2016. É valido ressaltar que entre os sites que constituem comunidades virtuais das marcas selecionadas estão o Facebook, Youtube e Twitter, porém, a rede social Youtube é limitada a postagens em vídeos, implicando em menor interação com os indivíduos. Dessa forma, para esta pesquisa, utilizou-se o Facebook e o Twitter como meio para obtenção dos dados, pois nestas redes sociais foram identificadas as páginas oficiais de cada uma das marcas em estudo. Além das páginas das marcas, foram selecionados grupos virtuais das marcas no Facebook. Para tanto, escolheu-se os grupos com maior número de usuários, verificando ainda as seguintes características propostas por Kozinets (2014), para o bom desenvolvimento da pesquisa netnográfica: relevantes, ativas, interativas, substanciais, heterogêneas e ricas em dados.

Delimitadas as unidades de análise procedeu-se a entrada e coleta de dados nas comunidades virtuais. Conforme Angrosino (2009), embora a internet seja uma espécie de espaço público, as pessoas que a utilizam têm os mesmos direitos que as pessoas em lugares mais convencionais. Portanto, a entrada nos grupos virtuais foi realizada por meio de postagens para apresentação, descrição da pesquisa e solicitação de permissão para realizar a pesquisa no grupo, obedecendo assim, os princípios éticos necessários.

Em relação aos tipos de dados coletados, a pesquisa incluiu a captura de três diferentes formas: dados arquivais, dados extraídos e dados de notas de campo (Kozinets, 2014). Os dados arquivais da pesquisa foram obtidos nas páginas oficiais e nos grupos virtuais das marcas, por meio da análise das postagens. Os dados extraídos foram obtidos por meio de questionários compostos predominantemente de questões fechadas, porém com algumas questões abertas e a possibilidade de inserir comentários. Ao fim da coleta dos dados, no final de 2016, obteve-se 96 questionários respondidos, tendo sido 36 pelos usuários das comunidades virtuais da marca Natura, 30 pelos usuários da marca Itaú e 30 pelos usuários da marca Skol. Ainda, considerou-se para a coleta dos dados as observações realizadas e anotadas como notas de campo.

Os dados quantitativos foram analisados conforme a estatística descritiva básica, enquanto que os dados qualitativos seguiram a análise de conteúdo, que consiste de uma descrição objetiva, sistemática e quantificada do conteúdo oriundo dos dados coletados, conforme explicita Malhotra (2012). Uma vez manipulados os dados e obtidos os resultados, o passo seguinte é a análise e interpretação dos mesmos, constituindo-se ambas no núcleo central da pesquisa (Marconi \& Lakatos, 2010). Posteriormente, a última etapa da pesquisa netnográfica é a redação e relato dos resultados. Dessa forma, compreendendo as duas últimas etapas, as descobertas obtidas nesta pesquisa são apresentadas no capítulo a seguir. 


\section{RESULTADOS E DISCUSSÃO}

Este capítulo está dividido em quatro seções, a saber: caracterização das comunidades virtuais; análise das funções das marcas; análise dos fatores internos dos usuários; análise comparativa multifocal.

\section{Caracterização das Comunidades Virtuais}

O Facebook e o Twitter, selecionados como fonte dos dados coletados para este estudo, possuem forma híbrida e apresentam particularidades, pois são redes sociais virtuais com características específicas que atraem públicos diversos. A denominação de forma híbrida se dá pois, de acordo com Kozinets (2014), apresentam-se como websites mas combinam em sua estrutura páginas de redes sociais com correio eletrônico, microblog, fóruns e salas de bate-papo.

Nessas redes sociais foram identificadas as páginas oficiais das marcas em estudo, além dos grupos virtuais no Facebook, que permitiram a extração de dados mais específicos. A imersão nas comunidades virtuais foi realizada durante oito meses variando o período em cada uma delas, mas sempre compreendidos entre os anos de 2015 a 2016.

A página oficial do Itaú no Facebook possuía mais de 8 milhões de curtidas. No período de coleta de dados foram feitas 12 novas postagens com vídeos ou links exclusivamente relacionados à marca. Entre os conteúdos acessíveis da página encontra-se: informações sobre o Itaú, fotos, curtidas, vídeos e eventos. No Twitter, a página do Itaú possuía mais de 15 mil seguidores, sendo iniciada em 2010 e apresentando-se como uma cópia da página existente no Facebook, inclusive no que consiste às postagens.

A página oficial da Skol no Facebook possuía mais de 12 milhões de curtidas, e postagens quase diárias de publicações. No período de coleta de dados foram feitas 19 novas postagens com vídeos, links, fotos e compartilhamentos. Entre os conteúdos acessíveis da página encontra-se: informações sobre a Skol, fotos, rádio Skol, eventos, vídeos e regras da página. No Twitter, a página da Skol possuía mais de 234 mil seguidores, tendo sido essa página iniciada em 2009 e apresentando aspectos visuais e postagens semelhantes à do Facebook.

A página oficial da Natura no Facebook possuía mais de 11 milhões de curtidas, e no período de coleta de dados foram feitas 25 novas postagens com vídeos, links e fotos, principalmente, relacionadas aos produtos, promoções e ações sociais da marca. No Twitter, a página da Natura possuía mais de 86 mil seguidores, tendo sido essa página iniciada em 2009 e com aspectos visuais semelhantes à página do Facebook, porém com menos postagens.

Os grupos virtuais selecionados no Facebook, para auxiliar na coleta de dados denominam-se: Amigos do Itaú; Skol aperte ON; Revista digital da Natura. As características desses grupos são abordadas de forma individual nos parágrafos seguintes. O grupo "Amigos do Itaú" possuía 688 membros e iniciou suas atividades em abril de 2015, neste mês observou-se que foi concentrada a maioria de suas postagens. Foi notório também a percepção da frequência de interações a partir das postagens e principalmente, que as mesmas estavam sempre associadas aos indivíduos deste grupo que se relacionam com a marca Itaú.

O segundo grupo estudado denomina-se "Skoll aperte ON" e possuía 1.011 usuários, as atividades se iniciaram em janeiro de $2016 \mathrm{com}$ um grupo de estudantes e se expandiu rapidamente a partir de indivíduos interessados pela marca. 0 último grupo estudado denomina-se "Revista digital da Natura", possuía 1.229 membros que começaram a interagir em novembro de 2011. Observou-se que a maioria das postagens aconteceu no período inicial do ano de 2015. Percebe-se, neste ponto, o expressivo volume de informações que é gerado dentro das comunidades virtuais e, por este motivo, justifica-se a importância do estudo para compreensão das mesmas, uma vez que elas se mostram indispensáveis na ação de estratégias mercadológicas por gestores de marcas.

\section{Funções das Marcas}

As funções das marcas analisadas neste estudo são as mesmas descritas por Kapferer (2003), a saber: referência, praticidade, garantia, otimização, personalização, permanência, hedonista e ética. Dessa forma, foram analisadas tais funções em cada uma das páginas e grupos das marcas extraídos 
nos dados coletados por esta pesquisa e os resultados são apresentados nos parágrafos e figuras a seguir.

\section{Itaú}

A primeira marca estudada é a Itaú, que foi eleita como a mais valiosa do Brasil no ano de 2015, apresentando um aumento de 13\% comparado ao ano anterior (Interbrand, 2016). A Figura 2 mostra os dados extraídos por meio dos questionários nas comunidades virtuais dessa marca, onde é possível observar que a maioria dos respondentes identificou a presença de todas as funções da marca, com destaque para as funções de referência e de personalização.

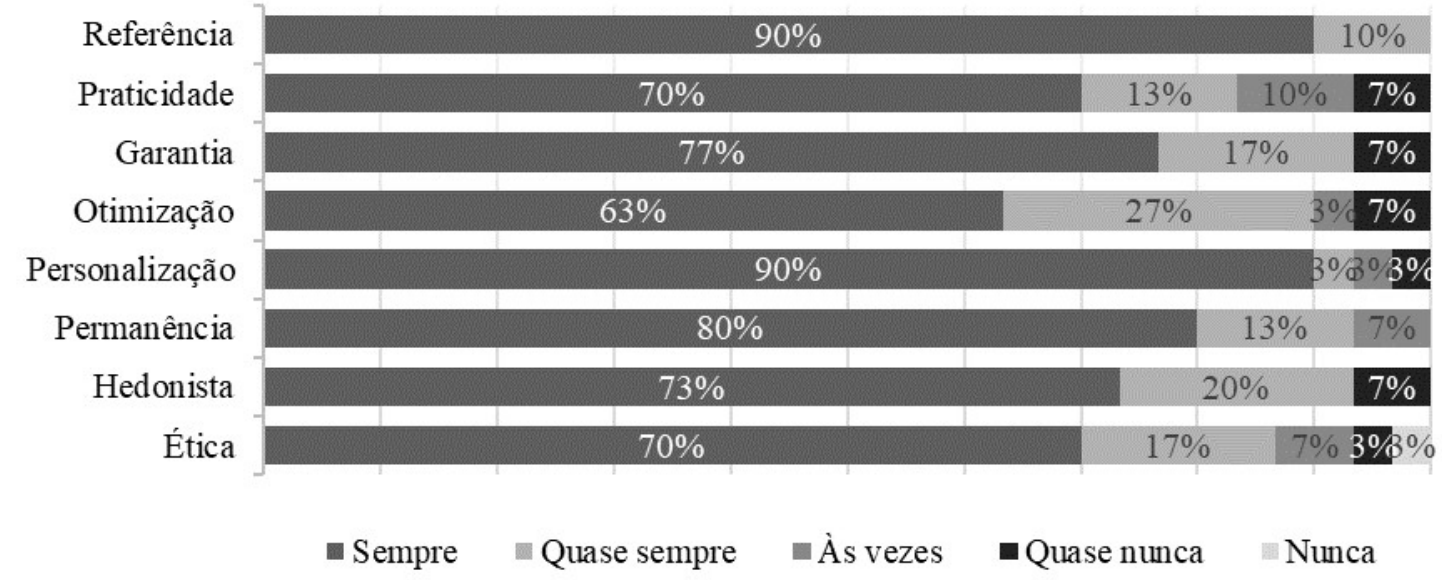

Fonte: Elaborado pelos autores.

Figura 2 - Funções das marcas para os usuários de comunidades virtuais da marca Itaú

Os dados obtidos de forma arquivais, evidenciam que os usuários da marca Itaú identificam a função de referência por meio de elementos como: o nome, logotipo, slogan, jingle e também as cores laranja e azul, que permitem associá-las diretamente à marca. A função de praticidade é relatada em comentários sobre a facilidade proporcionada pelos serviços oferecidos, além da rapidez no atendimento e da lealdade à marca. Tais dados ainda revelam que os usuários normalmente identificam a função de personalização ao postarem mensagens como: "banco feito para mim". A função de permanência é observada em comentários sobre a relação duradora com a marca.

Os comentários relacionados à função de garantia remetem à qualidade e agilidade dos serviços prestados, que também proporciona maior confiança. A função de otimização é identificada por meio de relatos relacionado à superioridade do atendimento e da comunicação com o cliente.

As postagens dos usuários relacionadas à função hedonista referem-se principalmente à satisfação em relação à comunicação da marca, incluindo o encantamento com as suas cores, sua identidade visual e os jingles. A função ética da marca é identificada por meio de ações sociais desenvolvidas pela marca, como por exemplo, leia para uma criança, cine Itaú cultural e bike Itaú.

\section{Skol}

A segunda marca estudada é a Skol, que demonstra sua força no mercado nacional ao se destacar entre outras quatro marcas mais valiosas do Brasil no setor de bebidas (Interbrand, 2016). Os dados extraídos por meio dos questionários são apresentados na Figura 3, e mostram que a maioria dos respondentes sempre identifica todas as funções da marca, com destaque para a função de otimização que está relacionada à segurança de comprar o melhor produto de sua categoria com o melhor desempenho (Kapferer, 2003). 


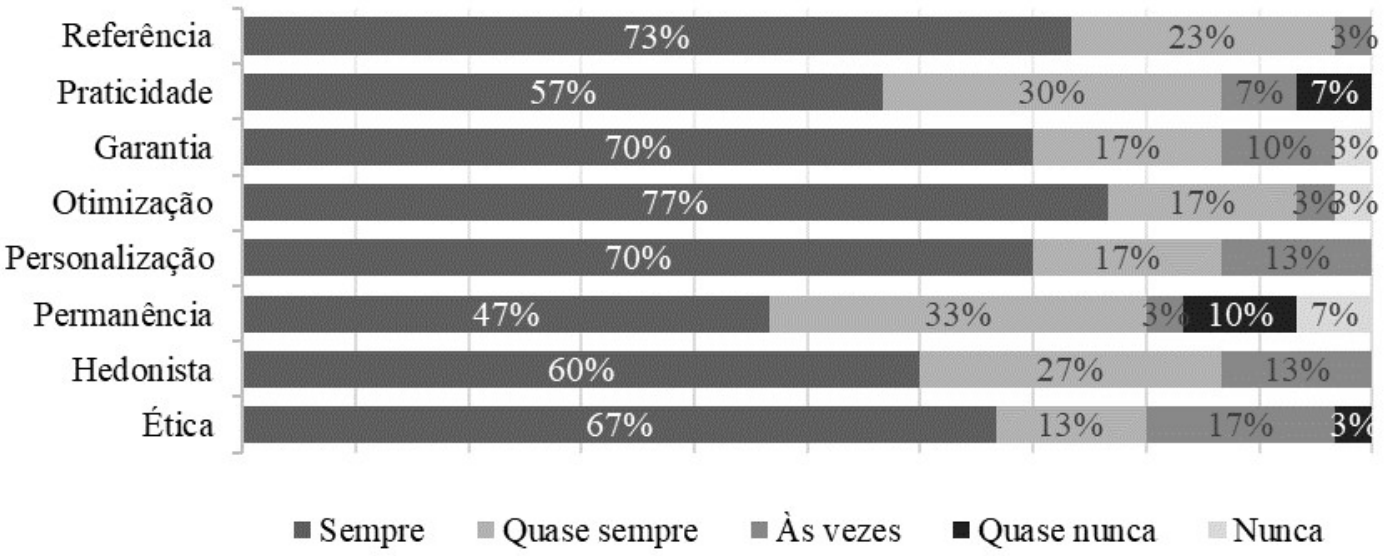

Fonte: Elaborado pelos autores.

Figura 3. Funções das marcas para os usuários de comunidades virtuais da marca Skol

Os dados obtidos de forma arquivais, evidenciam que os usuários da marca Skol identificam a função de referência por meio do seu nome, símbolo e slogan. A função de praticidade é evidenciada por alguns usuários que relatam a lealdade à marca. Estes dados ainda apontam que os usuários identificam a função de personalização ao evidenciar a imagem que desejam passar aos outros, como felicidade e juventude. A função de permanência é observada em comentários sobre a relação duradora com a marca.

A função de garantia é relatada pelos usuários ao comparar a qualidade dos produtos com outras marcas. Os comentários sobre a função de otimização demonstram o reconhecimento dos produtos Skol como os melhores da categoria. As postagens dos usuários relacionadas à função hedonista referem-se ao encantamento com o símbolo e slogan. A função ética da marca é identificada pelos usuários ao evidenciarem a importância do consumo responsável de bebida alcoólica.

\section{Natura}

A última marca estuda é a Natura, que é a sexta mais valiosa do Brasil, na categoria de cosméticos é a única representante entre as 25 mais valiosas, no entanto apresenta valor suficiente para figurar entre os três setores mais representativos (Interbrand, 2016). A Figura 4 mostra os dados extraídos por meio dos questionários, sobre as funções dessa marca. Conforme a figura, a maioria dos respondentes sempre identificam todas as funções da marca, com destaque para a função ética da marca. De acordo com Kapferer (2003), esta função tem o objetivo de proporcionar satisfação relacionada ao comportamento responsável da marca em suas relações com a sociedade. Os dados obtidos de forma arquivais, evidenciam que os usuários da marca Natura identificam a função de referência principalmente por meio do nome e slogan. A função de praticidade é relatada em comentários sobre a facilidade de compra dos produtos da marca.

Os comentários relacionados à função de garantia remetem à qualidade de diversos produtos da marca. A função de otimização é identificada por meio de relatos em que os usuários mencionam que o valor agregado justifica o preço superior dos produtos. Os dados arquivais ainda revelam que os usuários normalmente identificam a função de personalização ao postarem mensagens e imagens enfatizando a beleza e o bem-estar que são proporcionados pelos produtos da marca. A função de permanência é observada em comentários que relatam a familiaridade com os produtos que inclusive passa por diferentes gerações. 
Relacionando Funções das Marcas e Fatores de Influência Internos dos Usuários: Estudo netnográfico em comunidades virtuais

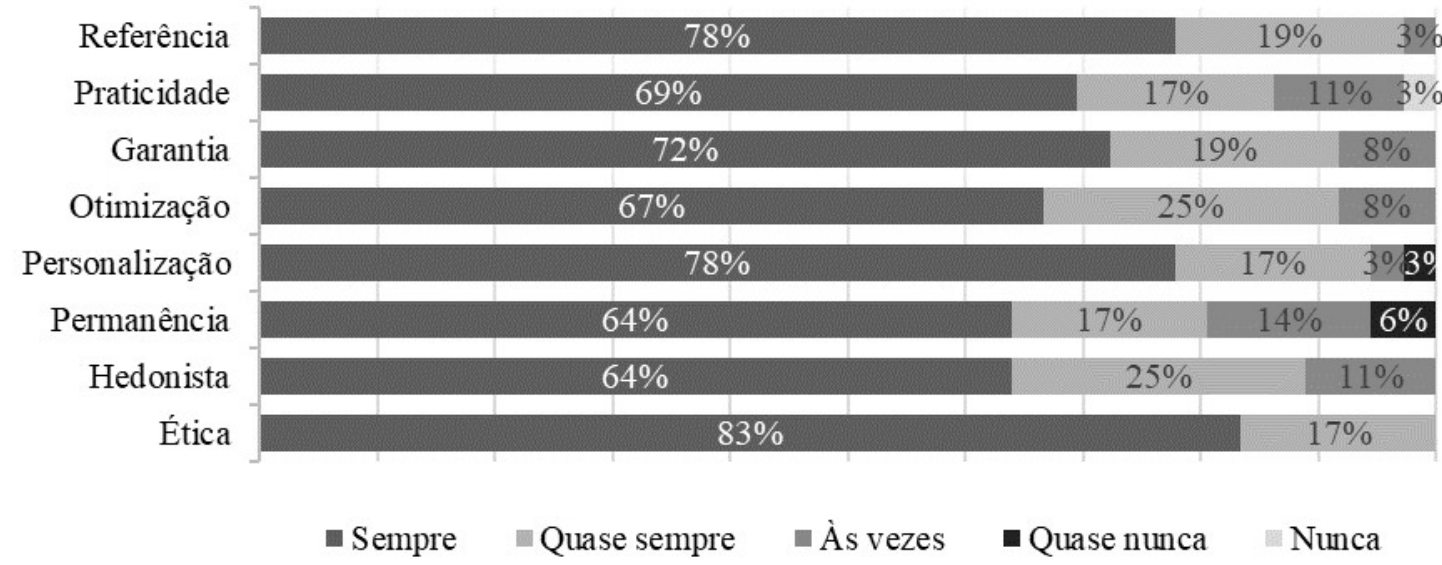

Fonte: Elaborado pelos autores.

Figura 4. Funções das marcas para os usuários de comunidades virtuais da marca Natura

As postagens dos usuários relacionadas à função hedonista referem-se principalmente à satisfação em relação à comunicação da marca. A função ética da marca é identificada por meio dos comentários que focam no comportamento responsável da marca, principalmente, no âmbito ambiental.

\section{Comparação das funções das marcas estudadas}

Os dados extraídos pelos questionários permitem, ainda, verificar quais funções de cada marca que apresentam maior grau de importância na percepção dos respondentes deste estudo. Estes dados são representados na Figura 5. Como mostra a figura, os respondentes da marca Itaú identificam com maior frequência as funções de referência e de personalização, enquanto que os da marca Skol identificam a função de otimização e, por fim, os da marca Natura identificam a função ética.

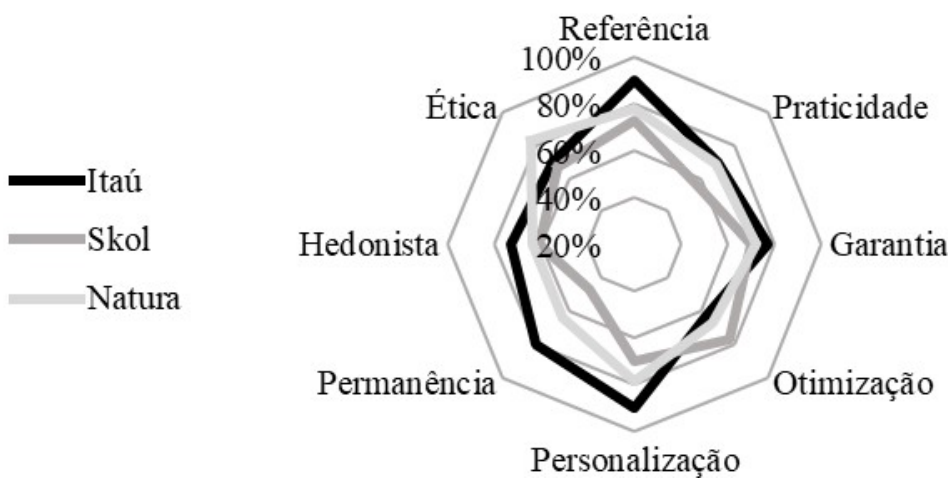

Fonte: Elaborado pelos autores.

Figura 5. Funções das marcas mais importantes para os usuários

A diferenciação entre as funções percebidas como mais importantes em cada uma das marcas pode-se dar por cada uma delas apresentar-se dentro de uma categoria diferente. Assim, o julgamento da importância de determinadas funções de marca, por parte dos respondentes, tende a se assimilar ao que eles compreendem como mais importante para determinada categoria. No caso, para serviços financeiros seria a referência e a personalização, para bebidas alcoólicas a otimização, e para a perfumaria e cosméticos a ética. Apresentados os dados referentes às funções das marcas para os indivíduos das comunidades virtuais, o próximo tópico apresenta a discussão dos dados sobre os fatores de influência internos dos usuários. 


\section{Fatores de Influência Internos dos Usuários}

Considerando a importância em examinar os fatores que influenciam a compra e o consumo, este tópico destina-se a analisar os fatores de influência internos dos usuários das comunidades virtuais. Os fatores de influência internos dos usuários analisados foram selecionados com base na revisão bibliográfica, os seguintes fatores foram utilizados: (1) motivação e necessidades; (2) desejos; (3) atitudes; (4) valores pessoais e (5) estilo de vida. Os dados coletados nas páginas e grupos das marcas de forma arquivais, extraídos ou em notas de campo são apresentados a seguir.

As motivações e necessidades, por serem relacionadas, foram abordadas em conjunto a partir de duas teorias, as motivações descritas por Schwartz e Bilsky (1990) e as necessidades de Maslow, ambas citadas por Rocha, Ferreira e Silva (2012). Assim os dados coletados foram analisados nas seguintes categorias:

Pró-social: proteção ao bem-estar dos demais;

Conformidade restritiva: restrição a atos e impulsos com o potencial de causar danos a outras pessoas ou violar normas sociais;

Prazer: gratificação emocional ou sensorial;

Realização: sucesso pessoal obtido graças à própria competência;

Maturidade: apreciação e aceitação de si mesmo, dos outros e do mundo;

Auto direcionamento: capacidade de pensar e decidir de forma autônoma;

Segurança: harmonia, estabilidade e segurança relativos a si mesmo, ao grupo social a que pertence e à sociedade.

Necessidade social: companheirismo, afeição, pertencimento social.

Ao analisar as motivações e necessidades dos usuários em relação as marcas, observou-se que os respondentes da marca Itaú consideram o fator segurança como o mais importante, enquanto os da Skol consideram a realização e os da Natura o fator pró-social. Outro fator interno de influência do consumidor é o desejo, que na concepção de Cobra (2009), pode ser composto de duas partes: explícito ou oculto. Para a maioria dos respondentes das três marcas, os desejos são considerados explícitos, pois eles afirmam que sabem o que querem da marca e conseguem falar o que desejam.

Ao pesquisar a atitude, foram analisados três fatores: cognitivo, afetivo e conativo. As atitudes cognitivas para a maioria dos usuários das três marcas são positivas em relação à marca. Para os usuários das marcas Skol e Itaú, geralmente se refere a qualidade, enquanto os pensamentos sobre a marca Natura são relacionados ao bem-estar e ao comportamento sustentável. Já no que se refere a atitude afetiva relacionada as marcas, a tranquilidade é a mais evidente para os respondentes da marca Itaú e Natura, já o componente relacionado à aventura é o mais importante para os respondentes da marca Skol. Sobre as atitudes conativas, verifica-se que a maioria dos respondentes possuem boas intenções em relação às três marcas estudadas, uma vez que os indivíduos têm a intenção de usá-las por longo prazo ou têm preferência pelas marcas apesar do interesse em outras marcas.

Os valores pessoais utilizados na coleta dos dados foram baseados no modelo de Schwartz, apresentado por Urdan e Urdan (2010) a qual abrange as seguintes dimensões de valor: tradição, benevolência, universalismo, auto direção, estimulação, realização e poder. A partir dos dados extraídos verifica-se que a auto direção está mais relacionada aos usuários da marca Itaú. 0 mesmo valor está ligado aos usuários da Skol, juntamente com a realização. Já os valores de tradição, benevolência e universalismo estão mais relacionados aos usuários da Natura.

0 estilo de vida dos indivíduos inclui as atividades, os interesses e as opiniões (Urdan \& Urdan, 2010). As atividades mais relacionadas às marcas são às de trabalho para Itaú e Natura e de diversão para Skol. Os principais interesses dos usuários da marca Itaú são relacionados à atividade profissional, enquanto para Skol refere-se ao lar e para Natura, a família. Por fim, as opiniões mais importantes para os usuários das marcas Itaú e Skol são as de si próprio e para os da Natura referemse aos negócios. Em síntese, os principais fatores de influência internos identificados nas comunidades virtuais são apresentados na Tabela 2 . 
Relacionando Funções das Marcas e Fatores de Influência Internos dos Usuários: Estudo netnográfico em comunidades virtuais

Tabela 2

Principais fatores de influência internos identificados

\begin{tabular}{|c|c|c|c|c|}
\hline & Itaú & Skol & Natura \\
\hline \multicolumn{2}{|c|}{ Motivação e necessidades } & Segurança & Realização & Pró-social \\
\hline \multicolumn{2}{|l|}{ Desejo } & Explícito & Explícito & Explícito \\
\hline \multirow{3}{*}{ Atitudes } & Cognitivas & Positivas & Positivas & Positivas \\
\hline & Afetivas & Tranquilidade & Aventura & Tranquilidade \\
\hline & Conativas & Melhores intenções & Boas intenções & Melhores intenções \\
\hline \multicolumn{2}{|c|}{ Valores pessoais } & Auto direção & $\begin{array}{l}\text { Auto direção e } \\
\text { realização }\end{array}$ & $\begin{array}{l}\text { Tradição, benevolência } \\
\text { e universalismo }\end{array}$ \\
\hline \multirow{3}{*}{$\begin{array}{l}\text { Estilo de } \\
\text { vida }\end{array}$} & Atividades & Trabalho e compras & Diversão & Trabalho e compras \\
\hline & Interesses & Atividade profissional & Lar/casa & Família \\
\hline & Opiniões & Si próprio & Si próprio & Negócios \\
\hline
\end{tabular}

Fonte: Elaborado pelos autores.

Apresentados os dados obtidos por meio da pesquisa netnográfica nas comunidades virtuais das marcas, o próximo tópico apresenta a relação entre as funções das marcas e os fatores de influência internos.

\section{Análise Comparativa Multifocal}

A partir dos resultados obtidos é possível estabelecer relações entre os fatores de influência dos usuários e as funções de cada uma das marcas estudadas, tais relações são demostradas na Figura 6 e explanadas em seguida. Em relação à marca Itaú é possível inferir que a função de referência está mais relacionada ao estilo de vida, pois as atividade e opiniões são comumente ligadas à atividade profissional nas comunidades virtuais estudadas. Já a função de praticidade está mais relacionada aos valores pessoais, haja vista que a auto direção, considerada importante para os usuários, proporciona facilidades que implicam na escolha da marca.

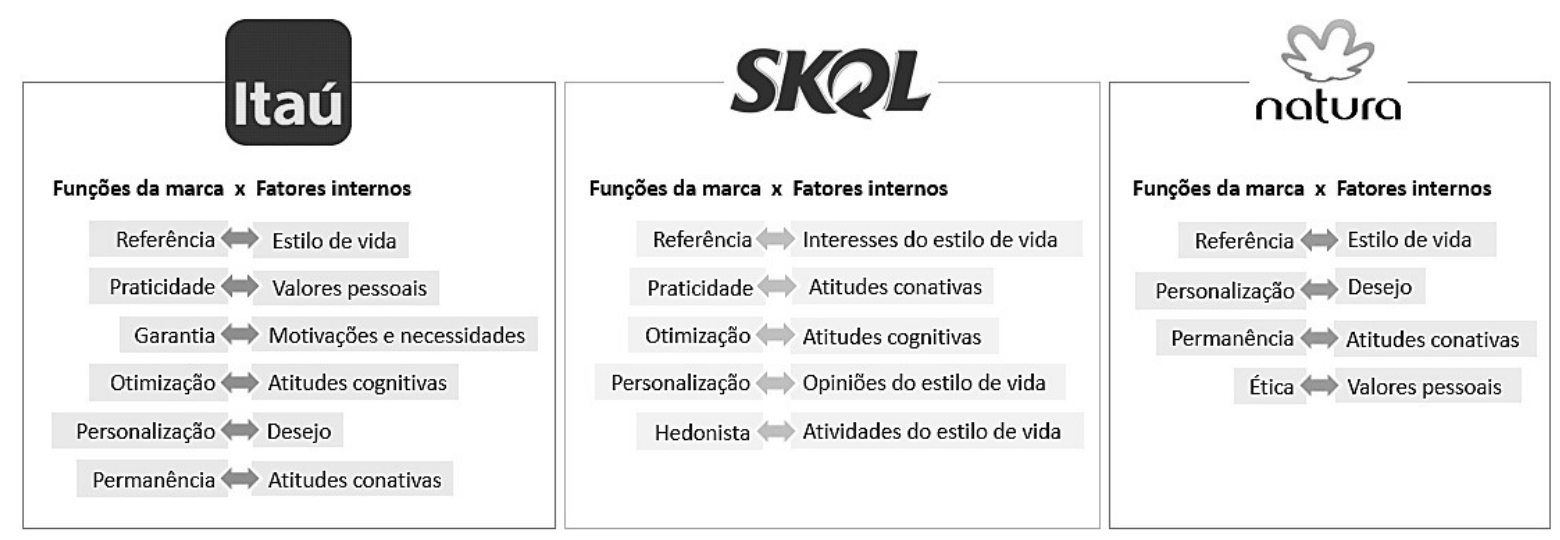

Fonte: Elaborado pelos autores.

Figura 6. Análise comparativa das funções das marcas com os fatores internos

Também é possível observar a relação da função de garantia com as motivações e necessidades devido ao fato de a segurança ser relatada como o principal fator motivacional que proporciona garantia para obter os serviços do Itaú. Além disso, a função de otimização está diretamente relacionada às atitudes cognitivas, pois os pensamentos dos usuários normalmente estão ligados à eficiência dos serviços da marca. Ainda em relação à marca Itaú é possível estabelecer relação entre a função de personalização com os desejos, devido às menções observadas nas comunidades virtuais sobre o desejo dos usuários de obter serviços personalizados. Por último, a função de permanência está mais relacionada às atitudes conativas, pois as intenções dos usuários da marca mostram uma relação duradora. 
Ao realizar a análise comparativa sobre a marca Skol verificou-se que as atitudes e o estilo de vida estão mais relacionados às funções, sendo que a função de praticidade está mais relacionada ás atitudes conativas, devido à preferência pela marca. Já a função de otimização está mais relacionada às atitudes cognitivas, pois os pensamentos dos usuários normalmente são ligados à superioridade dos produtos da Skol.

O estilo de vida dos usuários da Skol pode ser relacionado à três funções da marca, a função de referência mais relacionada aos interesses do estilo de vida, pois os usuários relatam seu interesse na marca relacionando-o ao lar ou casa. A função de personalização tem relação com as opiniões do estilo de vida, já que os usuários consideram as opiniões de si próprio como o mais importante. Por fim, verifica-se que a função hedonista tem maior relação com as atividades do estilo de vida, pois é comum postagens dos usuários demonstrando seu encantamento com a marca em momentos de diversão.

$\mathrm{Na}$ análise comparativa sobre a marca Natura identificou-se que as funções de referência, personalização e permanência possuem a mesma relação que as da marca Itaú, pelos mesmos motivos também. No entanto, destaca-se a relação da função ética com os valores pessoais, já que os usuários consideram o universalismo um dos valores mais importante, o que inclui o fator de preservação ambiental, comumente encontrado nas postagens dos usuários. Após a apresentação dos resultados e discussões, o capítulo seguinte expõe as considerações finais deste estudo.

\section{CONSIDERAÇÕES FINAIS}

A presente pesquisa teve o objetivo de compreender as funções das marcas e os fatores de influência internos para os usuários de comunidades virtuais das marcas Itaú, Skol e Natura. Dessa forma, inicialmente, foi possível identificar e selecionar comunidades virtuais das marcas mais valiosas em diferentes categorias, a partir das redes sociais Facebook e Twitter, onde foram identificadas as páginas oficiais destas marcas e os grupos virtuais. A partir da utilização de questionários, netnografia e análise de dados arquivais, configurou-se a caracterização das comunidades virtuais e identificou-se as funções de marca mais importantes na percepção dos respondentes deste estudo.

A caracterização das comunidades virtuais possibilitou verificar que as páginas das marcas possuem diferentes características e conteúdos acessíveis, enquanto os grupos virtuais possuem diferenças em suas estruturas e, principalmente, no tipo de interação dos usuários. Um ponto a ser ressaltado é que as marcas buscam manter uma padronização em suas páginas, não considerando a diferenciação de público que possa existir entre redes sociais diferentes. Isso é perceptível ao se analisar que não somente a identidade visual como as postagens eram semelhantes nas páginas das marcas no Facebook e no Twitter.

Ao analisar as funções das marcas observou-se que a maioria dos usuários que responderam ao questionário de pesquisa, sempre identificam, mesmo que inconscientemente, as funções das marcas descritas por Kapferer (2003) e utilizadas na realização deste estudo. Acerca destas funções, constatou-se que os respondentes da marca Itaú identificam com maior frequência as funções de referência e de personalização, os da marca Skol identificam a função de otimização e os da marca Natura identificam a função ética. No entanto, considerando que cada marca selecionada é de uma categoria diferente, deve-se ter consciência de que marcas de uma mesma categoria podem apresentar mesmo grau de importância para determinadas funções de marca.

No que diz respeito à análise dos fatores de influência internos dos usuários, por sua vez, foi possível identificar os componentes mais relevantes para os seguidores de cada marca, bem como foi possível realizar a análise comparativa entre os fatores de influência internos e as funções de cada marca, constatando-se que a marca Itaú possui mais itens relacionados às diferentes funções. Em relação à marca Skol, observou-se que as atitudes e o estilo de vida estão mais relacionados às suas funções. E, quanto à marca Natura, destaca-se a relação da função ética com os valores pessoais. Tais resultados evidenciam a gestão acertada das três marcas estudadas, uma vez que o posicionamento adequado destas, propiciam a correspondente percepção das funções exercidas para seus usuários.

Ademais, o estudo das comunidades virtuais das marcas, mostrou-se importante para que profissionais de marketing possam planejar e oferecer propostas de maneira estratégica às 
organizações a partir dos resultados. Assim como na pesquisa realizada por Laroche et al. (2012), a qual os autores sugerem o uso da marca e o gerenciamento de impressões dos usuários em mídias sociais para melhorar a fidelidade da marca. Dessa forma, as comunidades virtuais constituíram um valioso recurso para elucidar os objetivos, assim como destacam Tomas, Meschgrahw e Alcantara (2012), ao enfatizarem a importância da internet ao estudar as redes sociais e o comportamento de compra do consumidor.

Em relação às limitações deste trabalho, podem ser apresentadas limitações metodológicas, uma vez que a abordagem qualitativa aplicada na coleta dos dados, não permite a generalização dos resultados obtidos; e, o fato da pesquisa ser netnográfica, tendo todos os dados sendo obtidos no ambiente virtual, também pode representar uma limitação na percepção de alguns autores e pesquisadores. Outra limitação que pode ser apontada refere-se ao fato de que o estudo não inclui análise do perfil dos usuários, o que não permite diferenciar os consumidores dos seguidores nas comunidades virtuais. Porém estas foram escolhas pertinentes ao objetivo do presente estudo.

Para além destas limitações, sugere-se como indicações de futuras pesquisas: estudos em comunidades virtuais de marcas com aplicação de métricas quantitativas; pesquisas de comportamento dos consumidores mesclando a netnografia com a etnografia; estudos que incluam a análise do perfil dos usuários. Tais sugestões proporcionariam uma visão mais abrangente acerca do comportamento do consumidor em relação às marcas, ampliando assim, as fronteiras acadêmicas na área e gerando importantes contribuições para práticas gerenciais nas organizações.

\section{Referências}

Aaker, J. L., Fournier, S. M., \& Brasel, S. A. (2004). When good brands do bad. Journal Consumer Research, 31, 1-16.

Aaker, D. A. (1998). Marcas: brand equity: gerenciando o valor da marca. Gulf Professional Publishing.

Alexa. (2016) Top sites in Brazil. Acesso em 07 nov. 2016. Disponível em: <http://www.alexa.com/topsites/countries/BR>.

Angrosino, M. (2009). Etnografia e observação participante. Porto Alegre: Artmed.

Ariely, D. (2000). Controlling the information flow: effects on consumers' decision making and preferences. Journal of Consumer Research, 27(2), 233-248.

Aureliano-Silva, L. (2017). O Efeito da Marca de Eventos Musicais com Diferentes Níveis de Congruência do Artista-Celebridade. Consumer Behavior Review, 1(1), 1-10.

Blackwell, R. D., Miniard, P. W., \& Engel, J. F. (2011). Comportamento do consumidor. São Paulo: Cengage Learning.

Bruhn, M., Schoenmueller, V., \& Schäfer, D. (2012). Are social media replacing traditional media in terms of brand equity creation? Management Research Review, 35(9), 770-790.

Chevalier, M., \& Mazzalovo, G. (2007). Pró logo. São Paulo: Panda Books.

Cipriani, F. (2011). Estratégia em mídias sociais: como romper o paradoxo das redes sociais e tornar a concorrência irrelevante. Rio de Janeiro: Elsevier.

Cobra, M. H. N. (2009). Administração de marketing no Brasil. 3ạ ed., Rio de Janeiro: Elsevier.

Fournier, S. (1998). Consumers and their brands: Developing relationship theory in consumer research. Journal of consumer research, 24(4), 343-373.

Holbrook, M. B. (1987). What is consumer research? Journal of Consumer Research, 14(1), 128-132.

Interbrand. (2016). Marcas brasileiras mais valiosas. Acesso em 07 maio 2016. Disponível em: $<$ http://www.rankingmarcas.com.br/2016/>.

Kapferer, J. (2003). As marcas, capital da empresa: criar e desenvolver marcas fortes. 3. ed. Porto Alegre: Bookman.

Kapferer, J. (2008). The new strategic brand management: creating and sustaining brand equity. 4르. ed., London: Kogan Page.

Keller, K. L., \& Machado, M. (2006). Gestão estratégica de marcas. São Paulo: Pearson.

Kozinets, R. V. (2014). Netnografia: Realizando pesquisa etnográfica online. São Paulo: Penso. 
Laroche, M., Habibi, M. R., Richard, M. O., \& Sankaranarayanan, R. (2012). The effects of social media based brand communities on brand community markers, value creation practices, brand trust and brand loyalty. Computers in Human Behavior, 28(5), 1755-1767.

Malhotra, N. K. (2012). Pesquisa de marketing: uma orientação aplicada. 6 ${ }^{\underline{a}}$ ed., Porto Alegre: Bookman.

Marconi, M. A., \& Lakatos E. M. (2010). Fundamentos de metodologia científica. 7a ed., São Paulo: Atlas. McCracken, G. (2011). Chief culture officer: how to create a living, breathing corporation. Basic Books.

Rocha, A., Ferreira, J. B., \& Silva, J. F. (2012). Administração de Marketing: conceitos, estratégias, aplicações. São Paulo: Atlas.

Sousa Júnior, J. H., \& Silva Júnior, A. S. (2018). O Consultor em Marketing Digital na perspectiva de Consultores e Empresários. Revista Pesquisa em Administração UFPE, 1(2), 63-77.

Sousa Júnior, J. H. (2018). "Vai uma carona aí?": Experiências de consumo colaborativo de usuários de aplicativo de caronas. Consumer Behavior Review, 2(Special Edition), 33-42.

Telles, A. (2011). A revolução das mídias sociais: Cases, conceitos, dicas e ferramentas. São Paulo: M. Books.

Tomas, R. N., Meschgrahw, R. P. \& Alcantara, R. L. C. (2012). As redes sociais e o comportamento de compra do consumidor: o reinado do "boca-a-boca" está de volta? Revista Brasileira de Marketing, 11(2), 120-147.

Urdan, F. T., \& Urdan, A. T. (2013). Gestão do composto de Marketing. 2ª ed., São Paulo: Atlas.

Urdan, F. T., \& Urdan, A. T. (2010). Marketing estratégico no Brasil: teoria e aplicações. São Paulo: Atlas.

Vergara, S. C. (2013). Projetos e relatórios de pesquisa em administração. 14aㅡ ed., São Paulo: Atlas.

Wheeler, A. (2012). Design de identidade da marca. 3a ed., Porto Alegre: Bookman.

Wood, L. (2000). Brands and brand equity: definition and management. Management Decision, 38(9), 662-669. 